\title{
Glucose Control of Basal Insulin Secretion in Diabetes
}

\author{
S. T. McCarthy, E. Harris, and R. C. Turner \\ Nuffield Department of Clinical Medicine, Radcliffe Infirmary, Oxford, U. K.
}

\begin{abstract}
Summary. The plasma insulin response to both a small increase and decrease in the plasma glucose has been studied in normal and diabetic, non-obese subjects. In a second investigation the plasma insulin concentrations were measured during a gradual reduction of the raised fasting plasma glucose of diabetes to normal levels. In both studies, diabetic patients were found to have a markedly impaired response of the fasting plasma insulin to small changes in plasma glucose. These results do not support the suggestion that stimulated and not basal insulin secretion is impaired in diabetes. Both modes of secretion are probably via the same B-cell release mechanism, which is deficient in diabetes. There was a gradation of response between maturity onset and juvenile onset diabetics.
\end{abstract}

Key words: Basal insulin secretion, hypoglycaemia, basal plasma glucose, diabetes.

Diabetic patients usually have normal fasting plasma insulin concentrations although they have increased basal plasma glucose levels [1]. The steady-state plasma insulin response to prolonged infusions of small amounts of glucose has been reported to be normal in diabetics $[1,2]$, although the plasma glucose concentrations are higher than in normal subjects. However, diabetics have a markedly deficient insulin response to an acute rise in plasma glucose $[1,3,5]$. It has been postulated that basal and stimulated insulin secretion are from different 'pools' $[1,6]$, and that in diabetes the basal insulin secretion 'pool' is intact while the 'acute pool', which provides stimulated insulin secretion, is defective [1].

The distinction between the two modes of insulin release partly depends on the apparently selective suppression of stimulated, but not basal, insulin secretion by adrenalin $[7,8]$. However, if the plasma glucose is kept constant, adrenalin has been shown to suppress both basal and stimulated insulin release [9]. This paper re-examines the effect of small changes of plasma glucose on insulin secretion to determine whether the basal insulin secretion in diabetics is normal or impaired. Fish insulin has been used to lower the plasma glucose so that plasma human insulin levels can be studied [10] in response to induced hypoglycaemia as well as hyperglycaemia. In one study the plasma insulin levels of normal and mildly diabetic subjects have been studied in rẹsponse to both a slight increase and decrease of the plasma glucose. In a second study the plasma insulin levels of diabetics have been studied in response to a gradual decrease of the raised plasma glucose to a normal level.

\section{Materials and Methods}

In the first study nine male diabetic patients, aged 50-68 years, who had been treated by diet alone, were studied. Diabetes had previously been diagnosed by an oral $50 \mathrm{~g}$ glucose tolerance test, although two subjects had borderline results (fasting, peak and two hour plasma glucose $6.3,6.1 ; 14.1,12.5$; and $6.2,6.1$ $\mathrm{mmol} / 1 \mathrm{respectively).} \mathrm{Seven} \mathrm{age-matched,} \mathrm{normal}$ male subjects, who were employees of a bank, were also studied. All subjects were less than $15 \%$ over their ideal body weight [11], and were given written instructions to eat at least $200 \mathrm{~g}$ carbohydrate per day for 3 days prior to being tested. On two non-consecutive days, in random sequence, and after an overnight fast the diabetic patients were given a $90 \mathrm{~min}$ intravenous infusion of either $1.5 \mathrm{mg} / \mathrm{kg} / \mathrm{min}$ glucose or $0.1 \mathrm{mU} / \mathrm{kg} / \mathrm{min}$ fish insulin, and were then studied for a further $90 \mathrm{~min}$. The normal subjects were given the same dose of fish insulin, but a $3 \mathrm{mg} / \mathrm{kg} / \mathrm{min}$ glucose 
Table 1. Change in plasma glucose and plasma insulin to the glucose and fish insulin infusions in 7 normal und 7 diabetic subjects. The insulin response $(\Delta I)$ is expressed in absolute terms, relative to the change in plasma glucose $(\Delta G)$, and also relative to the pre-infusion plasma insulin $(\% \Delta \mathrm{I} / \Delta \mathrm{G})$. (mean $\pm 1 \mathrm{SD})$

\begin{tabular}{|c|c|c|c|c|c|c|}
\hline & \multicolumn{3}{|l|}{ Glucose infusion } & \multicolumn{3}{|l|}{ Insulin infusion } \\
\hline & Normal subjects & Diabetic subjects & $\mathrm{p}$ & Normal subjects & Diabetic subjects & $\mathrm{p}$ \\
\hline$\Delta \mathrm{G} \mathrm{mmol} / \mathrm{l}$ & $1.19 \pm 0.47$ & $0.91 \pm 0.56$ & 0.33 & $-0.32 \pm 0.27$ & $-1.12 \pm 0.81$ & 0.001 \\
\hline $\begin{array}{l}\Delta \mathrm{I} \mu \mathrm{U} / \mathrm{ml} \\
\Delta \mathrm{I} / \Delta \mathrm{G}\end{array}$ & $5.11 \pm 2.31$ & $1.8 \pm 2.1$ & 0.003 & $-1.63 \pm 0.85$ & $-1.21 \pm 1.17$ & 0.31 \\
\hline $\begin{array}{l}\mu \mathrm{U} / \mathrm{mmol} \\
\% \Delta \mathrm{I} / \Delta \mathrm{G}\end{array}$ & $4.52 \pm 1.4$ & $1.76 \pm 2.36$ & 0.013 & $4.7 \pm 4.2$ & $1.99 \pm 2.16$ & 0.082 \\
\hline$\% / \mathrm{mmol}$ & $108 \pm 32$ & $12.5 \pm 12.8$ & 0.0001 & $99 \pm 95$ & $24 \pm 27$ & 0.036 \\
\hline
\end{tabular}
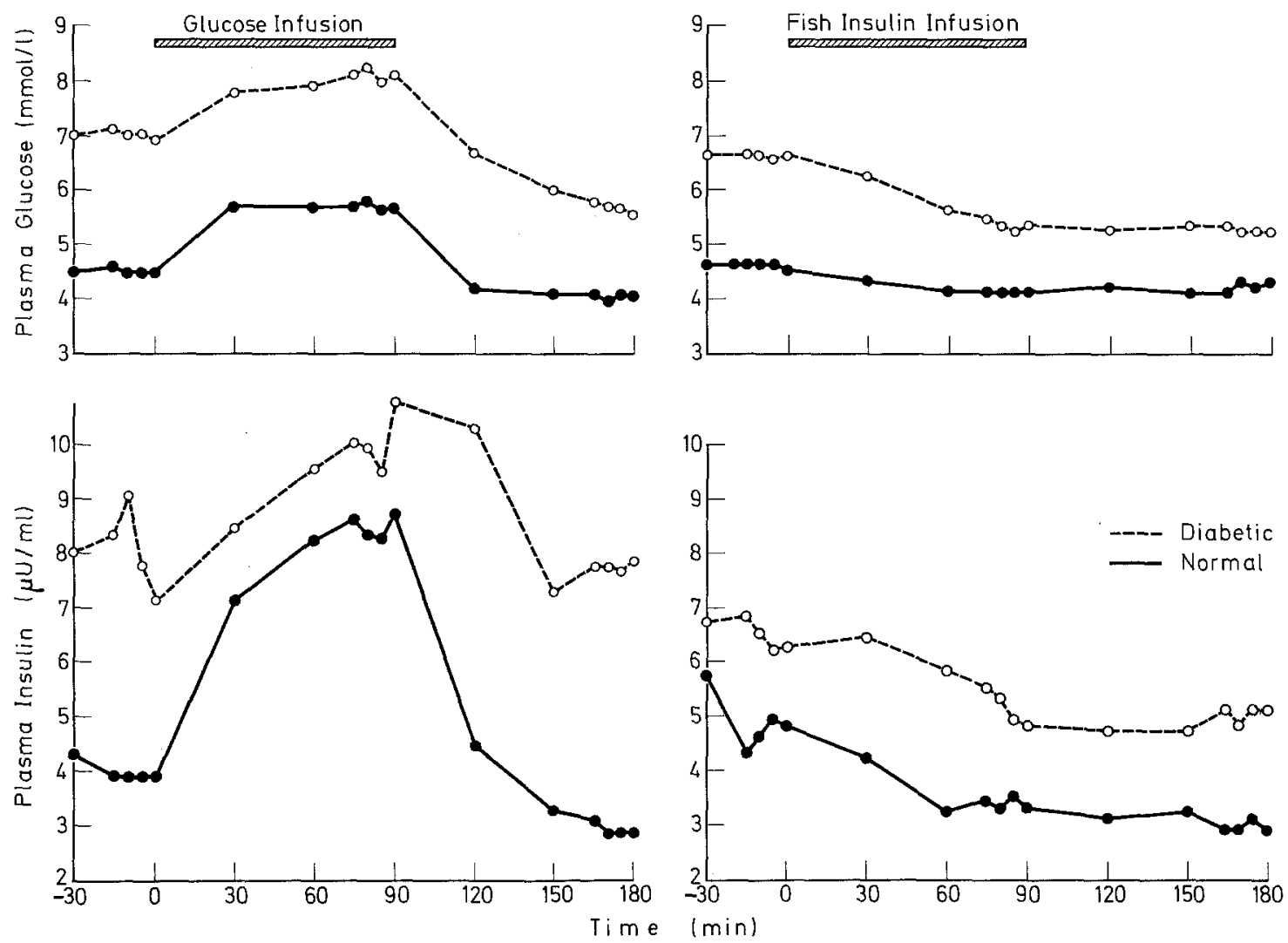

Fig. 1. Mean plasma glucose and insulin values in response to the glucose infusions and fish insulin in 7 normal subjects and in the 7 diabetic subjects who had a raised basal plasma glucose

infusion. Blood samples were taken at 5 min intervals for $15 \mathrm{~min}$ prior to the end of the infusion, and prior to the end of the subsequent rest period, and otherwise at 30 min intervals. Both the blood glucose and plasma insulin levels reached a plateau during the infusion periods; they are expressed as means of the last four samples taken at $5 \mathrm{~min}$ intervals.

In the second study 21 diabetic patients were studied during hypoglycaemia produced gradually by $0.2 \mathrm{u} / \mathrm{kg} \mathrm{i.m}$. fish insulin at $45 \mathrm{~min}$ intervals [10]. Blood samples were taken at 10 min intervals and the test stopped at the time of hypoglycaemic symptoms.
Eleven of the maturity onset patients were on dietary treatment, and were asked to eat at least $200 \mathrm{~g}$ of carbohydrate per day prior to tests. Six patients were newly diagnosed diabetics, 3 juvenile and 3 maturity onset, and were studied prior to therapy. Four severe juvenile diabetics who presented in pre-coma were studied 2-4 days after the onset of insulin therapy, fourteen hours after their last subcutaneous injection of soluble insulin. The normal subjects became hypoglycaemic after $1.5-2 \mathrm{~h}$, whereas the diabetics took up to $6 \mathrm{~h}$ before hypoglycaemic symptoms ensued and the test was stopped. 
Plasma glucose was measured manually using glucose oxidase (Boehringer kit). Plasma insulin was assayed using charcoal phase separation [12], and a sensitive ( $\pm 1 \mathrm{SD}, \pm 0.3 \mu \mathrm{U} / \mathrm{ml})$, disequilibrium assay using an antiserum (GP5, Dr. Lowy) which crossreacts little with fish insulin [10]. The significance of difference between means was measured by the Mann Whitney $U$ test, and correlation by Spearman's rank test, $\mathbf{r}_{\mathrm{s}}$.

\section{Results}

The diabetic subjects in the first study had fasting plasma glucose concentrations between 4.9 and $8.8 \mathrm{mmol} / 1$, with normal subjects having a fasting plasma glucose of $4.6 \pm 0.3$ (mean $\pm 1 \mathrm{SD}$, range $4.4-$ $5.0 \mathrm{mmol} / \mathrm{l}$ ). The changes following the glucose and insulin infusions are shown in Table 1, which excludes two diabetics who had fasting plasma glucose concentrations within the normal range. The remaining diabetics had a mean fasting plasma glucose of $6.8 \pm 1.1$ $\mathrm{mmol} / \mathrm{l}$. They had a slightly raised fasting plasma insulin concentration compared with the normal subjects (mean 7.4 and $4.4 \mu \mathrm{U} / \mathrm{ml}, \mathrm{p}<0.02$ ).

\section{Insulin Response to Small Changes in Plasma Glucose}

The normal and diabetic subjects had a similar rise in plasma glucose in response to the glucose infusions, but the diabetics had a significantly smaller plasma insulin response than the normal subjects (Fig. 1). This was more obvious if represented relative to the fasting plasma insulin and relative to the change in the plasma glucose (Table 1).

The diabetics had a greater plasma glucose fall than the normal subjects in response to the fish insulin infusion. In spite of this, the diabetics had slightly less plasma insulin depression than the normal subjects, the difference being significant when expressed relative to the fasting plasma insulin and to the change in plasma glucose (Fig. 1 and Table 1).

The insulin response of each subject to both a fall and rise in plasma glucose have been summed by a least-square, best fit straight line through the change in insulin and glucose concentrations expressed from the mean fasting plasma glucose for the two tests. The thus determined slope of the insulin response has been plotted against the mean fasting plasma glucose (Fig. 2). The diabetics have an insulin response which is markedly decreased in proportion to the degree of fasting hyperglycaemia.

\section{Insulin Sensitivity}

The insulin sensitivity, as judged by the fall in plasma glucose to the fish insulin infusion, was greater in

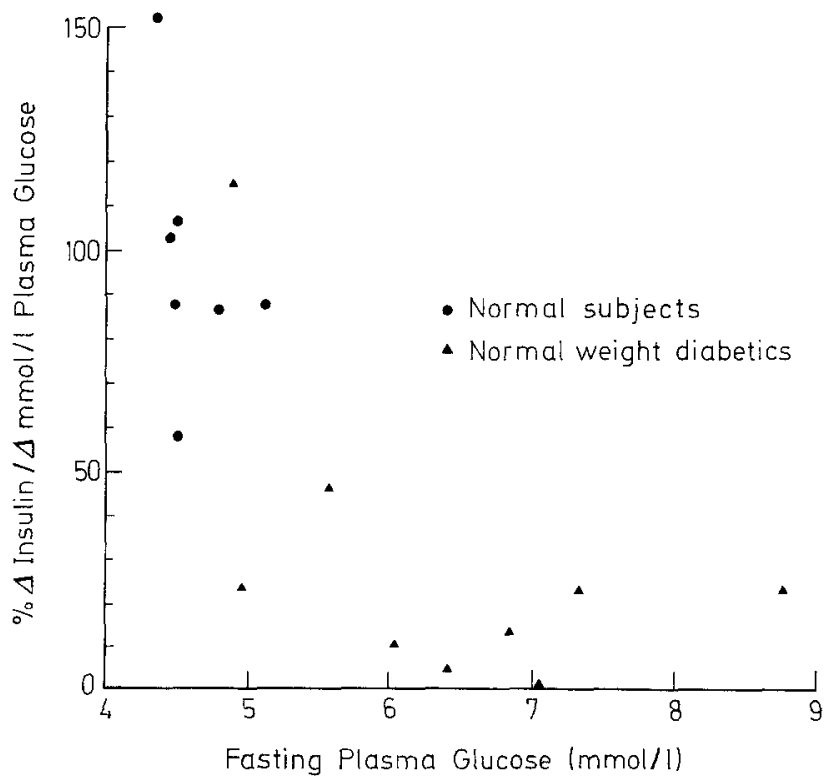

Fig. 2. Slope of the insulin response to small changes in plasma glucose shown in relation to the degree of diabetes as represented by the fasting plasma glucose

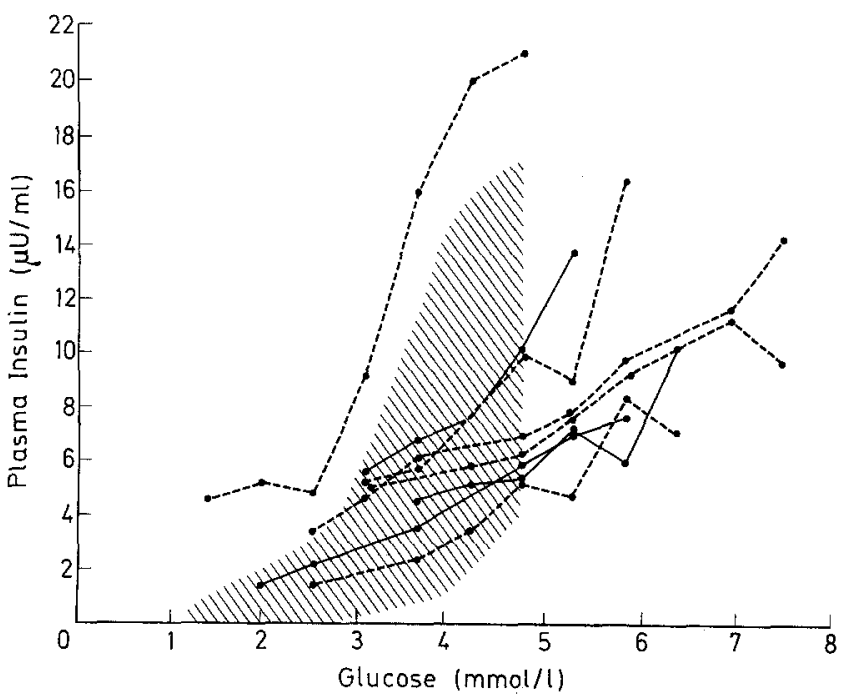

Fig. 3. Change in plasma insulin to a gradual reduction in plasma glucose induced by fish insulin in 8 diabetic patients with fasting plasma glucose $<8 \mathrm{mmol} / \mathrm{l}$. Blood samples were taken at $10 \mathrm{~min}$ intervals, and the plasma insulin shown is the mean of samples with plasma glucose grouped into $0.55 \mathrm{mmol} / \mathrm{l}$ ranges. Values from patients of normal weight are shown with a continuous line, and from patients weight $>15 \%$ over ideal body weight with broken lines. The shaded area represents the limits of 12 normal subjects to the same test

diabetics (Table 1) and significantly correlated in all subjects studied with the initial fasting plasma glucose $\left(\mathrm{r}_{\mathrm{s}}=0.70, \mathrm{p}<0.001\right)$. The fall in plasma glucose during the $90 \mathrm{~min}$ after the end of the glucose infusion was similarly greater in the diabetics (8.1 to 5.7 $\mathrm{mmol} / \mathrm{l})$ than in the normal subjects (5.7 to 4.1 


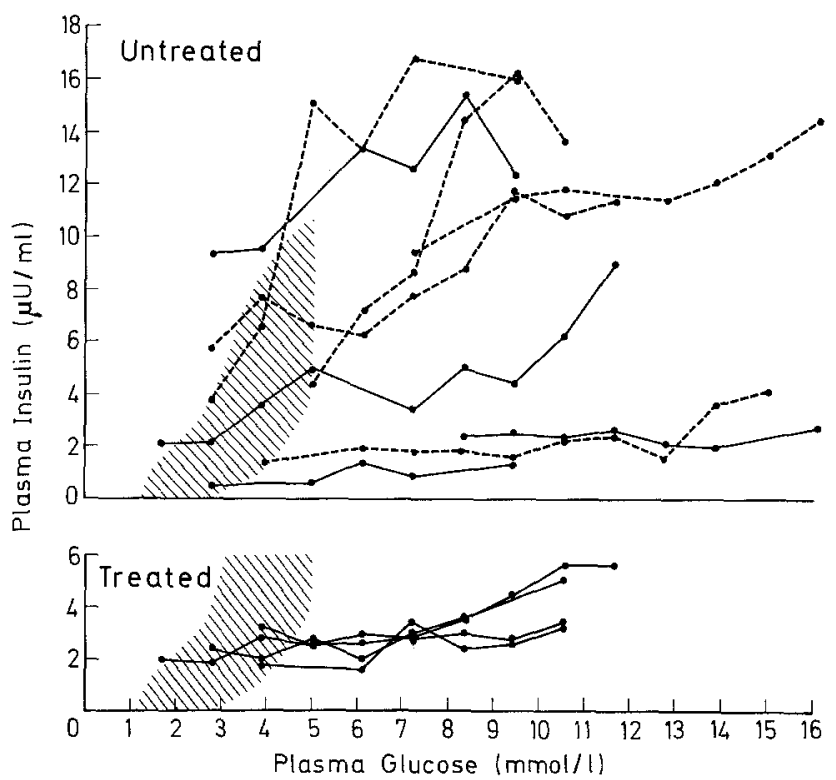

Fig. 4. Change in plasma insulin to a gradual reduction in plasma glucose in patients with fasting plasma glucose $>8 \mathrm{mmol} / 1$. See Figure 3 caption for details. Samples grouped into $1.1 \mathrm{mmol} / 1$ plasma glucose ranges

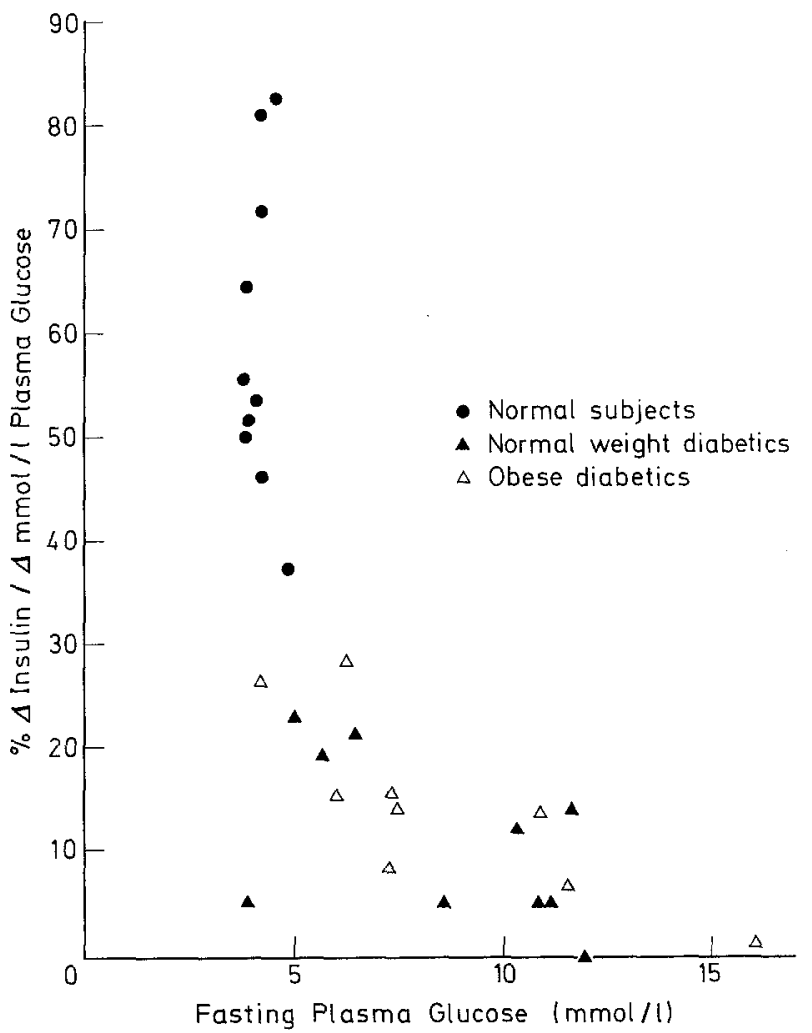

Fig. 5. Slope of the insulin response to large reductions in plasma glucose shown in relation to the degree of diabetes as represented by the fasting plasma glucose $\mathrm{mmol} / \mathrm{l})$, the fall being in proportion to the fasting hyperglycaemia $\left(r_{s}=0.55, p<0.01\right)$, even though the diabetics had a smaller insulin response than the normal subjects.

\section{Insulin Response to a Large Reduction of Fasting Plasma Glucose}

In the second study the plasma glucose in the diabetics was gradually reduced to a normal fasting concentration, although in several diabetic patients the investigation was terminated by a 'hypoglycaemic' reaction (sweating, pallor, tremor, palpitation) occurring whilst the patient remained hyperglycaemic (up to 6.5 $\mathrm{mmol} / 1$ plasma glucose). The plasma insulin levels decreased in the diabetics, but the suppression was less in relation to the plasma glucose than in the normal subjects (Fig. 3). In the more severe, non-obese diabetics the already low plasma insulin concentration remained fairly constant in spite of a substantial decrease in the plasma glucose (Fig. 4).

If the change in plasma insulin is expressed relative to the change in plasma glucose by a least-square best fit straight line through all the values of each subject (Fig. 5), the insulin response in diabetics was decreased to a similar extent as in the first study (Fig. 2).

\section{Discussion}

The results show that the response of basal insulin secretion in diabetics is impaired, compared with that of normal subjects, both to small changes in the fasting plasma glucose and to a large reduction of the plasma glucose to normal. These studies do not support the suggestion [1] that stimulated and not basal insulin secretion is impaired in diabetes.

The insulin response to the small rise in plasma glucose induced by the glucose infusion might be said to represent a stimulated response rather than a change in basal insulin secretion, although there is no criterion by which these can be distinguished. However, the insulin response to induced hypoglycaemia is a change in the basal insulin secretion which is unlikely to relate to the postulated "acute pool" which supplies stimulated insulin secretion $[1,6]$. Although insulin, in high doses, might directly suppress insulin secretion [13], low doses, as used in this study, have no effect on insulin secretion if the plasma glucose is kept constant [14]. Fish insulin injected in larger doses to dogs did not reduce insulin secretion [15].

The insulin response to small glucose changes is markedly impaired when the fasting plasma glucose is over $6 \mathrm{mmol} / \mathrm{l}$, but it is not as impaired as the acute, first phase insulin response to an intravenous glucose 
load, which is virtually absent at this level of basal hyperglycaemia [1]. The first phase insulin response may be limited either by the size of an "acute pool" or by the physiological characteristics of the B-cells [16], and the slightly different degree of impairment does not necessarily signify two separate modes of secretion.

Although the basal insulin levels are normal in diabetics, they arise either from a decreased number of normal B-cells or from impaired function of a normal number of B-cells. The normal B-cells are most responsive in the region of the overnight fasting glucose concentration [17]; if there were a decreased number of B-cells those remaining would have to function towards their maximal capacity [18]. This would result in a decreased capacity to respond to changes in plasma glucose, which would affect both the basal and stimulated insulin secretion. When the plasma glucose was slowly reduced to below the normal overnight fasting range the plasma insulin levels were not always suppressed to the same degree as in normal subjects, even though the samples were taken at a time when there was clinical evidence of raised catecholamine secretion. This impaired suppression of plasma insulin may result from a supra-normal rate of B-cell secretion which could not be quickly reverted. This response was found in both maturity onset and juvenile diabetic patients, and would be compatible with the possibility that both are due to a reduced number of B-cells [16]. Certainly there was a gradation in the B-cell response, with no qualitative difference, between all severities of diabetes.

The diabetic subjects had a greater fall in plasma glucose to both exogenous and endogenous insulin than the normal subjects. This is in accord with other studies [19]. The raised basal plasma glucose may be partly due to enhanced hepatic glucose efflux secondary to a diminished insulin secretory capacity $[18$, $20]$, in which case one might expect that increased plasma insulin levels would cause a greater fall in the plasma glucose in diabetics than in normal subjects.

Acknowledgements. We are grateful to Dr.T.D. R. Hockaday for allowing us to study his patients, to Professor D. J. Weatherall for his support, to the British Diabetes Association and the Oxford Regional Health Authority (Teaching) for grants.

\section{References}

1. Lerner, R. L., Porte, D.: Acute and steady state insulin response to glucose in non-obese diabetic subjects. J. Clin. Invest. 51, 1624-1631 (1972)
2. Goodner, C.J., Conway, J., Werrbach, J.: Control of insulin secretion during fasting hyperglycaemia in adult diabetics and in nondiabetic subjects during infusion of glucose. J. Clin. Invest. 48, 1878-1887 (1969)

3. Porte, D., Bagdade, J.D., Lerner, R.: Basal insulin secretion: The abnormality of obesity and its relation to a two-compartmental model for insulin release. Excerpta Med. (Amst.), Int. Congr. Series, 544-550 (1971)

4. Perley, M. J., Kipnis, D. M.: Plasma insulin response to oral and intravenous glucose; studies in normal and diabetic subjects. J. Clin. Invest. 46, 1954-1962 (1967)

5. Fujita, Y., Herron A. L., Seltzer, H. S.: Confirmation of impaired insulin response to glycaemic stimulus in non-obese mild diabetics. Diabetes 24, 17-27 (1975)

6. Porte, D., Pupo, A. A.: Insulin responses to glucose: evidence for a two pool system in man. J. Clin. Invest. 48, 2309-2319 (1969)

7. Lerner, R. L., Porte, D.: Epinephrine; selective inhibition of the acute insulin response to glucose. J. Clin. Invest. 50, 2453-2457 (1971)

8. Robertson, R.P., Porte, D.: Adrenergic modulation of basal insulin secretion in man. Diabetes 22, 1-8 (1973)

9. Turner, R. C., Hart, G., London D. R.: Adrenalin suppression of basal insulin secretion in man. Diabetologia 13, 19-24 (1977)

10. Turner, R. C., Johnson, P. C.: Suppression of insulin release by fish-insulin-induced hypoglycaemia with reference to the diagnosis of insulinomas. Lancet 1973 I, 1483-1485

11. Net weight standard for men and women. Statistical bulletin, Metropolitan Life Assurance Co., 40 Nov-Dec, 1-4 (1959)

12. Albano, J.D.M., Ekins, R.P., Maritz, G., Turner, R. C.: A sensitive, precise, radioimmunoassay of serum insulin relying on charcoal separation of bound and free hormone moieties. Acta Endocrinol. (Kbh.) 70, 487-509 (1972)

13. Iversen, J., Miles, D. W.: Evidence for a feed back inhibition of insulin on insulin secretion in the isolated, perfused canine pancreas. Diabetes 20, 1-9 (1971)

14. Morishta, S., Shima, K., Tanaka, R., Tarui, S.: Effects of exogenous insulin on secretory function of B-cells in man. Abstracts VI Int. Congr. Endocr., p. 96. Hamburg 1976

15. Sando, H., Kanazawa, Y., Kuzuya, T.: Effects of bonito insulin on endogenous insulin secretion in dogs. Am. J. Physiol., 218, 1357-1362 (1970)

16. Turner, R. C., Holman, R. R.: Insulin secretion in diabetic and normal man. In: Topics in diabetes (eds. K. G. M. M. Alberti, T. D. R. Hockaday). London: Heinemann 1977

17. Lerner, R.L., Porte, D.: Relationships between intravenous glucose loads, insulin responses and glucose diappearance rate. J. Clin. Endocr. 33, 409-417 (1971)

18. Turner, R.C., Holman, R. R.: Insulin rather than glucose homeostasis in the pathophysiology of diabetes. Lancet $1976 \mathrm{I}$, 1272-1274

19. Stimmler, L., Mashiter, K., Snodgrass, G. I. A. I., Boucher, B., Abrams, M.: Insulin disappearance after i.v. injection and its effect on blood glucose in diabetic and non-diabetic children and aduits. Clin. Sci. 42, 337-344 (1972)

20. Madison, L. L.: Role of insulin in the hepatic handling of glucose. Arch. Intern. Med. 123, 284-292 (1969)

Received: April 20, 1976, and in revised form: November 15, 1976

Dr. R. C. Turner, Medical Tutor

Nuffield Dept. of Clinical Medicine

The Radcliffe Infirmary

Oxford OX 2 6HE

U. K. 